\title{
ANALISIS DEFECT DAN KUALITAS PRODUK WRITING AND PRINTING PAPER DENGAN SIX SIGMA
}

\author{
Nurul Aziza1, Muhammad Afandi² \\ Teknik Industri, Fakultas Teknik \\ Universitas Maarif Hasyim Latif, Sidoarjo, Indonesia \\ e-mail : ${ }^{1}$ nurul_aziza@dosen.umaha.ac.id, ${ }^{2}$ fndmhmmd20@gmail.com \\ Diterima: 18 April 2018. Disetujui : 15 Juni 2018. Dipublikasikan : 29 Juni 2018 \\ (C)2018 -TESJ Fakultas Teknik Universitas Maarif Hasyim Latif. Ini adalah artikel dengan \\ akses terbuka di bawah lisensi CC BY 4.0 (https://creativecommons.org/licenses/by/4.0/)
}

\begin{abstract}
ABSTRAK
Persaingan di industri yang semakin ketat, mendorong perusahaan untuk lebih mengembangkan dan mencari cara agar proses produksi dapat berjalan efisien dan efektif. Salah satu produk yang dihasilkan oleh perusahaan adalah writing dan printing paper recycle (WPR) yang berusaha menekan angka defect yang dirasakan masih tinggi. Six sigma sebagai salah satu tool dalam peningkatan kualitas dengan target 3,4 kegagalan per sejuta kesempatan untuk setiap transaksi setiap produk barang dan jasa dengan mengaplikasikan siklus define, measure, analysis, improve, dan control (DMAIC) yang bersifat teknik pengendalian dan peningkatan kualitas dalam bidang manajemen kualitas. Dengan menggunakan metode six sigma, kualitas WPR dan dihasilkan perusahaan cukup baik yaitu 3,19 sigma dengan tingkat defect 45.005 untuk sejuta produksi (DPMO). Implementasi peningkatan six sigma pada penelitian ini menyimpulkan bahwa terdapat 5 (lima) faktor yang menyebabkan defect yaitu dirtcount sebanyak 41.670 ton, gramature sebanyak 32.103 ton, caliper sebanyak 30.799 ton, brightness sebanyak 28.909 ton, coppsize sebanyak 26.911 ton. Diantara kelima jenis defect yang dihasilkan, faktor dirtcount adalah penyebab dominan. Dengan six sigma dapat diketahui juga bahwa indeks Cpm sebesar 2,6140 yang berarti bahwa perusahaan dianggap kompetitif dalam persaingan.
\end{abstract}

Kata kunci : defect, dpmo, dmaic, kualitas, six sigma, writing and printing paper recycle

\section{PENDAHULUAN}

Perkembangan industri sangat berkembang pesat di Indonesia, yang mengakibatkan makin kompleksya tingkat persaingan pasar. Hal inilah yang memicu perusahaan untuk mempertahankan market share agar mampu mempertahankan dan bahkan meningkatkan penjualan. Menurut (Gaspersz, 2007) pengendalian kualitas adalah teknik operasional dan aktifitas yang digunakan untuk meningkatkan permintaan akan kualitas. Oleh sebab itu perusahaan selalu dituntut untuk meningkatkan kualitas produk yang dimulai dari berkualitasnya proses di lini produksi agar bisa berjalan secara efisien dan efektif. Namun kenyataannya sering terjadi penyimpangan yang menghasilkan produk yang dikategorikan sebagai produk cacat (defect). Untuk melakukan pengendalian kualitas, ada beberapa pendekatan pengendalian kualitas yang dipilih yang sesuai dengan kriteria yang tepat bagi perusahaan (Ahyari, 1990). Demikian halnya dengan industri kertas, raw material yang digunakan adalah serat kayu yang diolah sedemikian rupa menjadi pulp. Semakin lama ketersediaan kayu sebagai bahan dasar pulp semakin menipis sehingga harga pulp kertas menjadi mahal. Hal ini yang mendorong perusahaan untuk menggunakan bahan kertas bekas (recycle) sebagai bentuk program efisiensi produksi. Dampak penggunaan raw material yang berasal dari bahan bekas menyebabkan produk dengan tingginya defect.

Six sigma adalah metode yang dipakai dalam penelitian ini dikarenakan metode ini mampu menjawab terkait peningkatan kualitas dalam manajemen kualitas menuju target 3,4 kegagalan per sejuta kesempatan untuk setiap kegiatan produksi (Gaspersz, 2005). Penerapan Six sigma mampu diaplikasikan pada berbagai bidang yaitu pada proyek konstruksi dalam artikel (Latief \& Utami, 2009). Penelitian ini juga didasarkan atas penelitian sebelumnya yaitu aplikasi six sigma dan kaizen (Susetyo \& Winarni, 2011). Juga penelitian (Bozek \& Hamrol, 2012) tentang analisis lean production dan six sigma pada produksi perusahaan. Maka bisa dikatakan bahwa six sigma adalah hasil revolusi terakhir dari quality improvement yang berkembang sejak tahun 1940an (Manggala, 2005).

\section{METODE PENELITIAN}


Metode penelitian yang digunakan dalam penelitian ini adalah metode six sigma yang diterapkan pada bidang manufacturing, maka ada 6 aspek yang perlu diperhatikan yaitu sebagai berikut:

1. Mengidentifikasi karakteristik produk yang memuaskan pelanggan (sesuai kebutuhan dan harapan konsumen).

2. Mengklasifikasikan semua karakteristik kualitas sebagai CTQ (Critical To Quality).

3. Menentukan apakah setiap CTQ tersebut dikendalikan melalui pengendalian material, mesin proses dan lain-lain.

4. Menentukan batas toleransi untuk setiap CTQ apakah sesuai keinginan konsumen (menentukan UCL dan LCL dari setiap CTQ).

5. Menentukan maksimum variasi proses untuk setiap CTQ (menentukan standar deviasi untuk setiap CTQ).

6. Mengubah desain produk dan atau proses produksi sedemikian rupa agar mampu mencapai nilai target six sigma

Konsep penelitian ini diperlihatkan pada gambar 1 .

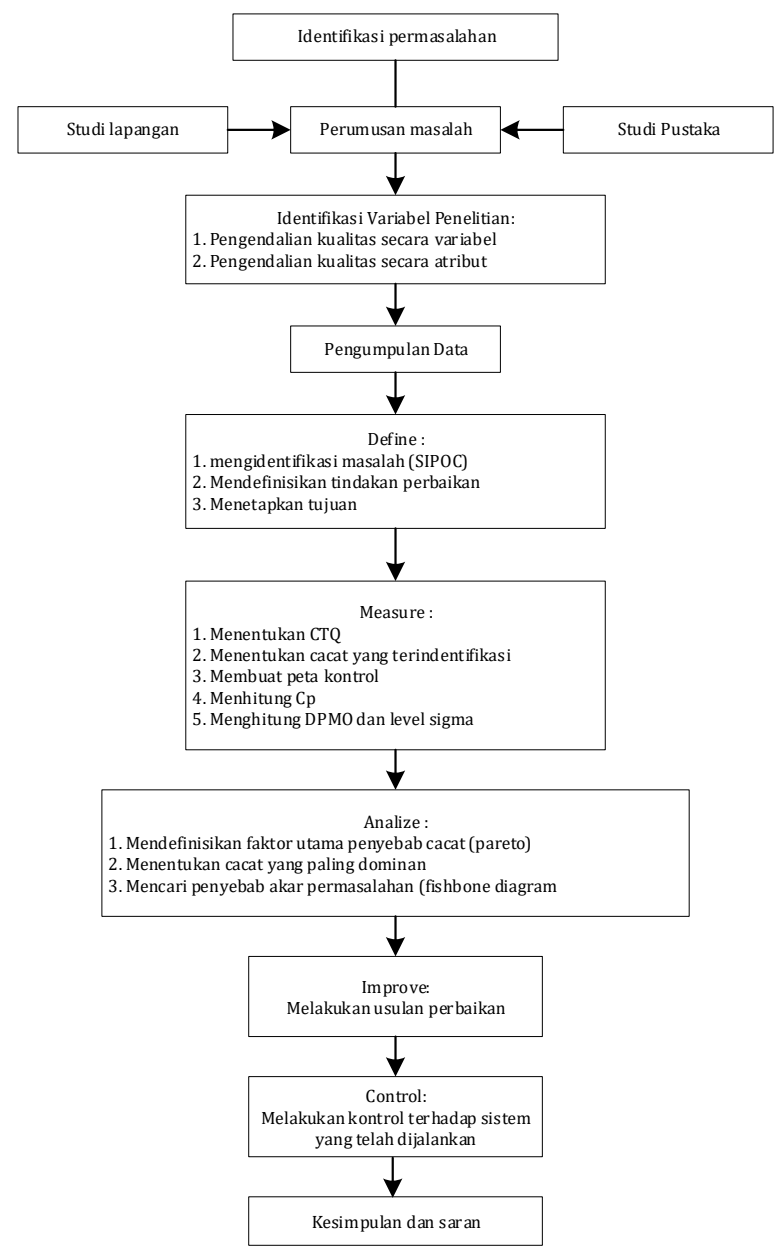

Gambar 1. Konsep berpikir penelitian

Sedangkan langkah analisis tingkat sigma dan DPMO dapat diihat pada tabel 1.
Tabel 1. Langkah analisis tingkat six dan DPMO

\begin{tabular}{cll}
\hline Langkah & \multicolumn{1}{c}{ Tindakan } & \multicolumn{1}{c}{ Persamaan } \\
\hline 1 & Proses apa yangingin diketahui & \\
2 & Barapa unit diproduksi & \\
3 & Berapa banyak produk cacat & \\
4 & Menghitung tingkat cacat & Langkah $3 / 4$ \\
& berdasarkan poin 3 & Banyaknya \\
5 & Menentukan CTQ penyebab & karakteristik CTQ \\
& produkcacat & Karakteristik CTQ \\
6 & Menghitung peluang cacat & katakteristikCTQ \\
7 & $\begin{array}{l}\text { Menghitung kemungkinan cacat } \\
\text { per DPMO }\end{array}$ & Langkah 6 x 1.000.000 \\
8 & $\begin{array}{l}\text { Konversi DPMO kedalam nilai } \\
\text { sigma }\end{array}$ & \\
\hline & &
\end{tabular}

\section{Pengumpulan Data}

Langkah awal adalah dengan membuat diagram SIPOC (supplier - input - process - output customers). Diagram SIPOC dapat digambar pada gambar 2.

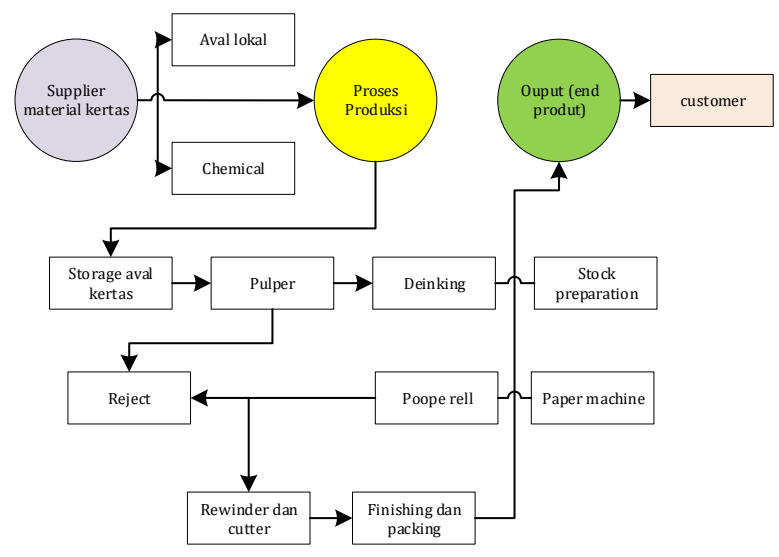

Gambar 2. Diagram alir proses produksi

Penjelasan dari gambar 2, sebagai berikut:

1. Storage aval kertas HVS:

- Proses diawali dari penerimaan material berupa aval HVS sebagai bahan dasar pembuatan WPR.

- Sebelum proses aduk di pulper terlebih dahulu aval HVS dengan memisahkan beberapa kriteria kertas yang tidak bisa hancur yang biasanya berupa kertas yang mengandung lem.

2. Pulper, yaitu proses penghancuran kertas menggunakan metode high consistency pulper (HCP) dengan menggunakan bahan chemical tertentu.

3. Deinking, adalah serangkaian proses pemisahan tinta yang terkandung dalam serat kertas dengan metode enzim. Dalam proses deinking ini terdapat beberapa proses critical yang meliputi bleaching, floatyasing dan washing .

4. Stock preparation, yaitu sistem pengolahan struktur slurry kertas dengan mengkondisikan struktur serat terhadap kebutuhan bahan baku ideal dalam pembuatan WPR. Dalam proses ini yang paling critical adalah consistency, freeness, 
dan adjusment warna menggunakan $O B A$ dan Dyes.

5. Paper machine,adalah mesin pembuat kertas yang mengubah slurry menjadi kertas dengan serangkaian proses screener, preasing, penambahan enzim, size press, drying hingga menjadi kertas.

6. Poope rell, adalah sejenis poros yang terbuat dari besi yang digunakan untuk kertas setelah proses di paper machine. Dalam tahap ini kertas tergulung dalam poros besi yang dinamakan jumbo roll.

7. Rewender dan cutter, yaitu urutan proses dalam satu lini dengan produksi. Proses rewender adalah proses gulung baik paper dari poope rell yang bertujuan memperbaiki struktur kertas menjadi lebih baik dan halus. Setelah digulung balik, kertas langsung terpotong sesuai ukuran yang diinginkan dan langsung tertata rapi diatas pallet, proses ini dinamakan proses cutter.

8. Finishing dan packing, yaitu proses akhir dalam pembuatan WPR yang meliputi proses finishing yaitu cutting dengan ukuran A4 ataupun A3 sesuai dengan order cutting yang direncanakan. Setelah proses cutting selesai, paper dipacking dalam karton yang siap dipasarkan.

9. End product, yaitu produk akhir yang dikemas dalam karton yang disimpan dalam gudang barang jadi sebelum dikirim untuk memenuhi kebutuhan konsumen.

\section{HASIL DAN PEMBAHASAN}

Berdasarkan pengumpulan data hasil produksi didapatkan 5 (lima) penyebab defect yang menjadi penyebab potensial dalam menghasilkan produk WPR yaitu sebagai berikut:

1. Kertas kotor (dirt count > spesifikasi), yaitu adanya bintik-bintik hitam pada paper yang disebabkan kurang terangkatnya tinta dengan sempurna pada proses floatasi di deinking. Bintik hitam ini mempengaruhi kualitas visual kertas pada saat digunakan dalam proses print, fotokopi atau pencetakan lainnya.

2. Copp size, yaitu ketahanan paper terhadap resapan air. Parameter propertis ini menggunakan satuan gr $/ \mathrm{m}^{2}$.

3. Warna pudar (brightness), warna pudar dalam industri kertas disebut dengan brightness. Semakin tinggi nilai brightness maka akan semakin cerah warna kertas dan begitupun sebaliknya.

4. Caliper, merupakan ketebalan dari ply paper dalam satuan micron. Dalam hal ini kertas tidak boleh terlalu tipis karena akan menyebabkan tinta tembus pada saat proses print dan tidak boleh terlalu tebal karena akan menyebabkan berkurangnya end product.
5. Gramature, yaitu berat kertas yang dihitung dengan membandingkan berat/meter persegi $\left(\mathrm{gr} / \mathrm{m}^{2}\right)$.

Berikut adalah jumlah cacat pada masing-masing jenis cacat pada produksi WPR pada gambar 3 .

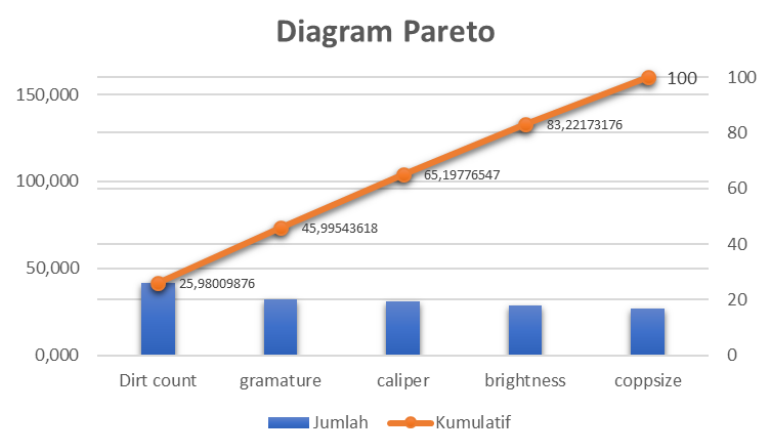

Gambar 3. Jenis cacat dan jumlah cacat

\section{Analisis Diagram Kontrol (P-Chart)}

- Menghitung mean (p) atau rata-rata proporsi produk cacat dengan rumus:

$$
p=\frac{\sum n p}{n}
$$

- Menetapkan peta kendali proporsi kesalahan model rata-rata dengan rumus:

$$
n=\frac{\text { total produksi }}{\text { jumlah observasi }}
$$

- Menetapkan batas kendali atas (UCL)

$$
U C L=p+\sqrt{\frac{p(1-p)}{n}}
$$

- Menetapkan batas kendali bawah (LCL)

$$
U C L=p-\sqrt{\frac{p(1-p)}{n}}
$$

Hasil perhitungan batas kendali atas dan batas kendali bawah dapat dilihat pada gambar 4 .

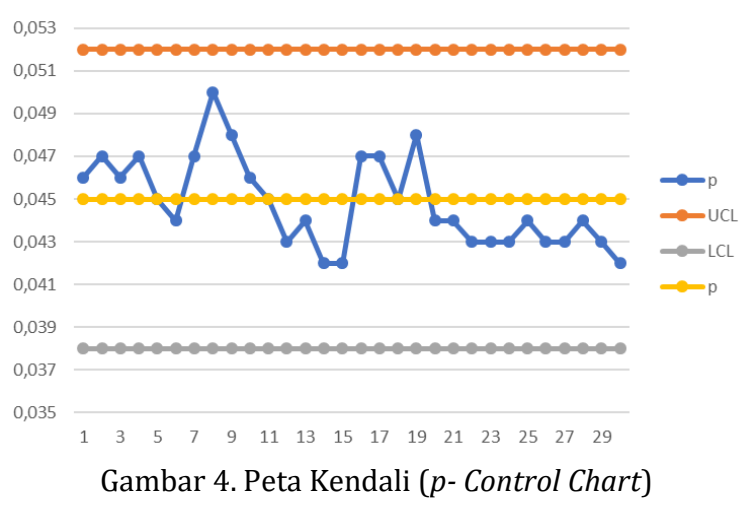

Berdasarkan gambar 4 peta kendali, data menunjukkan bahwa masih dalam batas kendali atas dan kendali bawah, namun masih relatif tinggi karena rata-rata proporsi defect masih mencapai 0,045 atau 4,5\%. Hal ini menyatakan bahwa masih 
perlu dilakukan perbaikan kualitas hingga mencapai nilai terendah sebesar $0 \%$.

\section{Perhitungan DPMO}

Untuk mengukur tingkat six sigma dari hasil produksi dilakukan dengan menggunakan rumus:

- Menghitung DPU (defect per unit)

$$
D P U=\frac{\text { total cacat produk }}{\text { jumlah produksi }}
$$

- Menghitung menghitung DPMO (defect per million opportunities)

$$
D P M O=\frac{\text { total cacat produk }}{\text { jumlah produksi }} \times 1.000 .000
$$

- Mengkorversikan hasil perhitungan DPMO dengan tabel six sigma untuk mendapatkan nilai sigma.

Berdasarkan hasil perhitungan, didapatkan ratarata nilai sigma 3,19 dengan kemungkinan kerusakan sebanyak 45.004 sejuta produksi. Hal menyebabkan kerugian yang sangat besar bagi perusahaan.

\section{Perhitungan Process Capability}

Indeks Cpm digunakan untuk mengukur kapabilitas potensial atau yaang melekat dari suatu proses yang diasumsikan stabil, yang bisa dirumuskan sebagai berikut:

$$
C p m=\frac{(U C L-L C L)}{\sqrt{(\mu-T)^{2}+\sigma^{2}}}
$$

Dengan nilai $\sigma^{2}$ didapatkan dari rumus:

$$
\sigma^{2}=\frac{\sum_{i-1}^{N}\left(x_{i}-\mu\right)^{2}}{N}
$$

Dengan asumsi $\mathrm{T}$ (target defect) maksimal 5\% maka diperoleh :

$$
\begin{aligned}
& T=5 \% \times \mu \text { produk } \\
& T=5 \% \times 118.797 \\
& T=5,940
\end{aligned}
$$

Dengan demikian, maka nilai Cpm dapat diketahui.

$$
\begin{aligned}
C p m & =\frac{(0,052-0,038)}{\sqrt{(0,045-0,05)^{2}+0,00000373}} \\
C p m & =\frac{0,014}{0,005535575} \\
C p m & =2,61401292
\end{aligned}
$$

\section{Diagram Sebab Akibat}

Diagram sebab akibat menunjukkan hubungan antara permasalahan yang dihadapi dengan kemungkinan penyebabnya serta faktor lain yang mempengaruhinya. Berdasarkan hasil wawancara dan survei lapangan, didapatkan

\begin{tabular}{|c|c|c|c|}
\hline Faktor & Faktor penyebab & Standar normal & Usulan perbaikan \\
\hline \multirow[t]{2}{*}{ Mesin } & Tinta sulit terangkat & $\begin{array}{l}\text { Putaran poros flotasi } 80- \\
90\end{array}$ & $\begin{array}{l}\text { Putaran poros flotasi tidak stabil, perlu dijadwalkan kegiatan } \\
\text { kalibrasi secara rutin }\end{array}$ \\
\hline & Kerja enzim kurang maksimal & Tekanan screw otomatis & Sebaiknya dilakukan setting manual \\
\hline \multirow[t]{2}{*}{ Manusia } & $\begin{array}{l}\text { Settingan mesin deinking kurang } \\
\text { pas sehingga performansi mesin } \\
\text { menurun }\end{array}$ & Sudah diseting & $\begin{array}{l}\text { Perlu adanya training untuk operator baru yang belum } \\
\text { berpengalaman }\end{array}$ \\
\hline & $\begin{array}{l}\text { Konsumsi enzim dan chemical } \\
\text { lainnya tidaksesuai takaran }\end{array}$ & $\begin{array}{l}\text { Sudah ada standar } \\
\text { komposisi yang pas }\end{array}$ & $\begin{array}{l}\text { Perlu adanya pengawasan saat adjusment chemical dan } \\
\text { enzim sehingga bisa meminimalkan ketidaktelitian operator }\end{array}$ \\
\hline \multirow[t]{2}{*}{ Material } & $\begin{array}{l}\text { Kualitas enzim dan chemical } \\
\text { menurun }\end{array}$ & $\begin{array}{l}\text { Telah dicek kualitas dan } \\
\text { kuantitas saat produk } \\
\text { datang }\end{array}$ & $\begin{array}{l}\text { Perlu adanya recheck berkala sampai enzim dan chemical } \\
\text { digunakan saat proses proses produksi untuk mengetahui } \\
\text { apakah kondisi enzim masih stabil }\end{array}$ \\
\hline & $\begin{array}{l}\text { Terlalu banyak kandungan tinta } \\
\text { dan lem pada bahan aval }\end{array}$ & $\begin{array}{l}\text { Hanya check kuantitas } \\
\text { dan kelayakan visual }\end{array}$ & $\begin{array}{l}\text { Dilakukan kontrol pada tahap pulping sehingga mengetahui } \\
\text { kualitas slurry dan bisa dilakukan adjusment chemical di } \\
\text { tahap selanjutnya }\end{array}$ \\
\hline \multirow[t]{2}{*}{ Metode } & $\begin{array}{l}\text { Komposisi chemical tetap dan } \\
\text { tidak menyesuaikan kondisi awal }\end{array}$ & $\begin{array}{l}\text { Komposisi chemical sesuai } \\
\text { kondisi standar yang } \\
\text { ditetapkan }\end{array}$ & $\begin{array}{l}\text { Dilakukan pengamatan terhadap kecerahan aval sehingga } \\
\text { dapat menentukan takaran chemical yang diperlukan }\end{array}$ \\
\hline & $\begin{array}{l}\text { Komposisi enzim tetap dan tidak } \\
\text { menyesuaikan kondisi awal }\end{array}$ & $\begin{array}{l}\text { Komposisi enzim sesuai } \\
\text { kondisi standar yang } \\
\text { ditetapkan }\end{array}$ & $\begin{array}{l}\text { Dilakukan pengamatan terhadap kondisi aval sehingga } \\
\text { dapat menentukan takaran enzim yang diperlukan }\end{array}$ \\
\hline Lingkungan & $\begin{array}{l}\text { Air terkontaminasi sehingga } \\
\text { menjadi kotor }\end{array}$ & $\begin{array}{l}\text { Air melalui water } \\
\text { treatment }\end{array}$ & $\begin{array}{l}\text { Dilakukan perlakuan pengulangan pada water treatment } \\
\text { sehingga didapatkan kadar air yang acceptable }\end{array}$ \\
\hline
\end{tabular}
gambar 5 diagram sebab akibat penyebab kecacatan.

Langkah selanjutnya adalah menyusun suatu rekomendasi usulan perbaikan yang bersifat umum dalam upaya meminimasi tingkat kecacatan produk yaitu seperti yang dapat dilihat pada tabel 2.

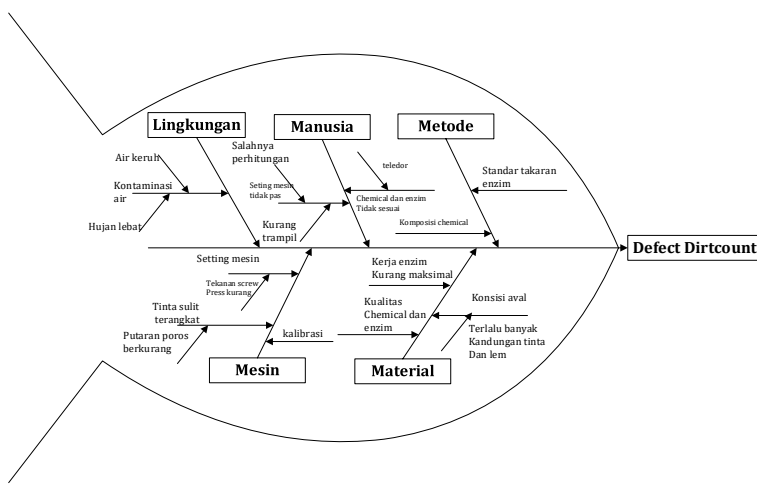

Gambar 5. Diagram sebab-akibat jenis cacat dirtcount

Tabel 2. Rekomendasi usulan tindakan perbaikan untuk jenis cacat dirtcount 


\section{PENUTUP}

Berdasarkan hasil dan pembahasan, faktor defect yang terjadi pada lini produksi untuk produk writing dan printing paper recycle (WPR) disebabkan karena dirtcount sebanyak 41.670 ton, jenis cacat gramature sebanyak 32.103 ton, jenis cacat caliper sebesar 30.799 ton, jenis cacat brightness sebesar 28.909 ton dan coppsize sebanyak 26.911 ton. Sehingga jenis cacat paling dominan adalah dirtcount. Dengan menggunakan pendekatan metode six sigma diketahui perusahaan memiliki nilai sigma 3,19 dengan kemungkinan kerusakan produk sebesar 45.005 ton untuk sejuta produksi (DPMO). Indeks Cpm $=2,1624$ dimana nilainya lebih besar dari 2, yang berarti perusahaan masih dianggap kompetitif dalam persaingan. Sebagai masukan bagi perusahaan, sebaiknya pengendalian kualitas dilakukan secara berkelanjutan dan berkesinambungan agar perusahaan mampu bersaing dengan mengurangi produk defect yang berakibat pula pada kerugian besar.

\section{DAFTAR PUSTAKA}

Ahyari, A. (1990). Pengendalian Produksi II. Yogayakarta: BPFE UGM.

Bozek, M., \& Hamrol, A. (2012). Analysis of efficiency of Lean Manufacturing and Six Sigma in a production enterprise. Management and Production Engineering Review, 3(4), 14-25.

Gaspersz, V. (2005). Integrated Performance management system the Balanced Scorecard with the Six Sigma for business and Government Organizations. Jakarta: Gramedia Pustaka Utama.

Gaspersz, V. (2007). Lean Six Sigma. Gramedia Pustaka Utama.

Latief, Y., \& Utami, R. P. (2009). Penerapan pendekatan metode six sigma dalam penjagaan kualitas pada proyek konstruksi. Makara Journal of Technology, 13(2).

Manggala, D. (2005). Six Sigma Secara Sederhana.

Susetyo, J., \& Winarni, C. H. (2011). Aplikasi Six Sigma DMAIC dan Kaizen sebagai metode pengendalian dan perbaikan kualitas produk. Jurnal Teknologi, 4(1), 53-61. 


\section{LAMPIRAN}

Tabel 3. Total produksi dan jumlah cacat

\begin{tabular}{|c|c|c|c|c|c|c|c|c|}
\hline & \multirow{2}{*}{$\begin{array}{c}\text { Jumlah produksi } \\
\text { (ton) }\end{array}$} & \multicolumn{5}{|c|}{ Jenis cacat } & \multirow{2}{*}{$\begin{array}{c}\text { Jumlah produk } \\
\text { cacat }\end{array}$} & \multirow{2}{*}{$\begin{array}{c}\text { produk cacat } \\
(\%)\end{array}$} \\
\hline & & Dirtcount & Coppsize & Brightness & Caliper & Gramature & & \\
\hline 1 & 119790 & 1450 & 900 & 930 & 1040 & 1140 & 5460 & 4,557976459 \\
\hline 2 & 115540 & 1386 & 800 & 920 & 1148 & 1209 & 5463 & 4,728232647 \\
\hline 3 & 119780 & 1285 & 900 & 1011 & 1078 & 1208 & 5482 & \begin{tabular}{|l|}
4,576723994 \\
\end{tabular} \\
\hline 4 & 118970 & 1418 & 989 & 1007 & 1104 & 1106 & 5624 & 4,727242162 \\
\hline 5 & 119030 & 1450 & 890 & 998 & 1130 & 890 & 5358 & 4,501386205 \\
\hline 6 & 119040 & 1478 & 879 & 970 & 1090 & 880 & 5297 & 4,449764785 \\
\hline 7 & 119140 & 1398 & 889 & 965 & 1080 & 1320 & 5652 & 4,743998657 \\
\hline 8 & 118140 & 1390 & 930 & 949 & 1179 & 1450 & 5898 & 4,99238192 \\
\hline 9 & 118780 & 1370 & 910 & 978 & 1060 & 1341 & 5659 & 4,764270079 \\
\hline 10 & 119070 & 1408 & 893 & 1023 & 989 & 1204 & 5517 & 4,633408919 \\
\hline 11 & 119370 & 1372 & 894 & 1021 & 997 & 1099 & 5383 & 4,509508252 \\
\hline 12 & 117990 & 1387 & 887 & 1045 & 940 & 800 & 5059 & 4,287651496 \\
\hline 13 & 119000 & 1367 & 896 & 891 & 1201 & 907 & 5262 & 4,421848739 \\
\hline 14 & 119040 & 1372 & 889 & 983 & 970 & 840 & 5054 & 4,24563172 \\
\hline 15 & 118750 & 1378 & 850 & 897 & 950 & 900 & 4975 & 4,189473684 \\
\hline 16 & 119550 & 1451 & 905 & 1021 & 993 & 1205 & 5575 & 4,663320786 \\
\hline 17 & 119750 & 1430 & 960 & 1034 & 996 & 1190 & 5610 & \begin{tabular}{|l}
4,684759916 \\
\end{tabular} \\
\hline 18 & 118900 & 1422 & 875 & 1189 & 801 & 1089 & 5376 & 4,521446594 \\
\hline 19 & 118850 & 1430 & 897 & 1012 & 1109 & 1209 & 5657 & \begin{tabular}{|l}
4,759781237 \\
\end{tabular} \\
\hline 20 & 119020 & 1398 & 800 & 800 & 1078 & 1109 & 5185 & 4,356410687 \\
\hline 21 & 119350 & 1397 & 940 & 840 & 1089 & 976 & 5242 & \begin{tabular}{|l}
4,392124005 \\
\end{tabular} \\
\hline 22 & 119430 & 1391 & 875 & 858 & 1054 & 996 & 5174 & 4,33224483 \\
\hline 23 & 118990 & 1345 & 901 & 879 & 999 & 1012 & 5136 & 4,316329103 \\
\hline 24 & 119010 & 1399 & 930 & 980 & 805 & 1045 & 5159 & 4,334929838 \\
\hline 25 & 118650 & 1388 & 895 & 934 & 991 & 1067 & 5275 & 4,445849136 \\
\hline 26 & 119450 & 1365 & 889 & 1023 & 979 & 900 & 5156 & 4,316450398 \\
\hline 27 & 118560 & 1347 & 991 & 1089 & 1010 & 999 & 5436 & \begin{tabular}{|l}
4,585020243 \\
\end{tabular} \\
\hline 28 & 118540 & 1362 & 980 & 907 & 1019 & 1001 & 5269 & 4,444913109 \\
\hline 29 & 117450 & 1257 & 807 & 889 & 1030 & 1020 & 5003 & \begin{tabular}{|l}
4,259684972 \\
\end{tabular} \\
\hline 30 & 116980 & 1379 & 870 & 875 & 890 & 991 & 5005 & 4,278509147 \\
\hline Total & 3563910 & 41670 & 26911 & 28909 & 30799 & 32103 & 160392 & 135,0212737 \\
\hline $\begin{array}{l}\text { Rata- } \\
\text { rata }\end{array}$ & 118797,00 & 1389,00 & 897,03 & 963,63 & 1026,63 & 1070,10 & 5346,40 & 4,500709124 \\
\hline Min & 115540 & 1257 & 800 & 800 & 801 & 800 & 4975 & \begin{tabular}{|l|l|}
4,189473684 \\
\end{tabular} \\
\hline $\operatorname{Max}$ & 119790 & 1478 & 991 & 1189 & 1201 & 1450 & 5898 & 4,99238192 \\
\hline
\end{tabular}

